\title{
Optimal Slot Opening Width for Magnetic Noise Reduction in Induction Motors
}

\author{
J. Le Besnerais, Student Member, IEEE, V. Lanfranchi, M. Hecquet, R. Romary, and P. Brochet, Member, IEEE
}

\begin{abstract}
This paper presents a method to characterize the main magnetic force waves occurring in a sinusoidally-fed induction machine. Three main force types are identified: slotting force waves, winding force waves and saturation force waves. Slotting force waves are characterized in terms of number of nodes, velocity, propagation direction and magnitude. On the ground of the expression of these forces magnitude, a method to cancel a given magnetic force wave by properly choosing the rotor slot or stator slot opening width is presented. This new method is validated with both simulations and experiments.

Contrary to the common design rule that advices to decrease rotor and stator slot openings width in order to reduce magnetic noise, it is shown that a wider slot opening can lower the global noise level when properly chosen.
\end{abstract}

Index Terms-Induction machine, magnetic noise, vibrations, Maxwell forces.

\begin{tabular}{ll} 
& \multicolumn{1}{c}{ NOMENCLATURE } \\
$b_{r}$ & Rotor slot opening width \\
$b_{s}$ & Stator slot opening width \\
$d_{f}^{r}$ & Rotor fictitious slot depth \\
$d_{f}^{s}$ & Stator fictitious slot depth \\
$f_{c}$ & PWM switching frequency \\
$f_{s}$ & Fundamental stator supply frequency \\
$f_{m m}^{s}$ & Stator magnetomotive force \\
$F_{s}$ & Stator mmf magnitude \\
$g$ & Air-gap width \\
$p$ & Number of pole pairs \\
$P_{r}, P_{s}$ & Rotor and stator slotting permeance \\
& harmonics magnitude \\
$s$ & Fundamental slip \\
$Z_{r}$ & Number of rotor slots \\
$Z_{s}$ & Number of stator slots \\
$\alpha_{s}$ & Angular position in stator steady frame \\
$\mu_{0}$ & Air-gap magnetic permeability \\
$\tau_{r}$ & Rotor slot pitch \\
$\tau_{s}$ & Stator slot pitch
\end{tabular}

\section{INTRODUCTION}

Manuscript received the 30th of September, 2008. This work was supported in part by the French Agence De l'Environnement et de la Maîtrise de l'Energie.

J. Le Besnerais is with the Laboratoire d'Electrotechnique et d'Electronique de Puissance (L2EP), Ecole Centrale de Lille, FRANCE (phone: (+33) 320 6760 20, e-mail:jean.le_besnerais@centraliens.net).

V. Lanfranchi is with the Laboratoire d'Electromécanique de Compiègne (LEC), Compiègne, FRANCE (e-mail: vincent.lanfranchi@utc.fr).

M. Hecquet and P. Brochet are also with the L2EP (e-mail: michel.hecquet@ec-lille.fr and pascal.brochet@ec-lille.fr).

R. Romary is with the Laboratoire Systèmes Electroniques et Environnement (LSEE), Université d'Artois, Béthune, FRANCE (e-mail: raphael.romary@univ-artois.fr).
A $S$ acoustic comfort becomes increasingly important in electrical transport systems, and especially in subways and light-rail vehicles where both passengers and frontage residents are exposed to noise, the understanding of magnetic noise generation becomes crucial. This source of noise, mainly due to the air-gap radial Maxwell forces that excite the stator in the audible range [1], creates unpleasant tonalities that are penalized by IEC 60349-2 standard [2].

Active noise-reduction technique of current injection [3], [4], [5] is not able to cancel magnetic force harmonics of spatial order different from 0 and $2 p$ : as the elliptical stator mode is usually the one that radiates the most, this technique cannot be applied to traction motors with 2 or 3 pole pairs. Other active techniques generally require expensive control loops and electromechanical devices. There is therefore a special need to find some efficient low-noise rules that can be applied during the motor design stage. Closing rotor slots, enlarging the air-gap or skewing the rotor are techniques that efficiently decrease magnetic noise but also significantly degrade motor performances.

This paper first presents a way to analytically characterize the main sources of magnetic noise in sinusoidally-fed induction motors. Three main sources of magnetic vibrations are identified, due to air-gap slotting harmonics, stator magnetomotive force ( $\mathrm{mmf}$ ) harmonics, and saturation harmonics. Slotting vibrations characteristics are detailed, and experimentally validated by visualizing the stator stack deflections at some given frequencies. The expression of slotting magnetic forces magnitude is then derived, and it is shown that it can be canceled by properly choosing the rotor or the stator slot opening width in some sets of optimal values. To validate this effect, some simulation results are then presented, and a new rotor prototype is built and successfully tested.

\section{MAGNetiC NOISE CHARACTERIZATION}

\section{A. Expression of radial Maxwell forces}

Neglecting the tangential component of the Maxwell tensor and magnetostrictive effect, the radial exciting pressure $P_{M}$ that is supposed to be responsible for magnetic noise can be approximated by [6], [7], [8]

$$
P_{M}=B_{g}^{2} /\left(2 \mu_{0}\right)
$$

where $B_{g}$ is the radial air-gap flux density. Assuming that the rotor is not skewed, and neglecting end effects, this force is independent of the axial direction and can therefore only excite some circumferential modes of the stator stack, which can be modeled by an equivalent ring as a first approximation. 
Developing the magnetic pressure (1) in two-dimensional Fourier series, it can be expressed as a sum of progressive force waves of time frequency $f$ and space frequency $m$ (also called spatial order):

$$
P_{M}\left(t, \alpha_{s}\right)=\sum_{m, f} A_{m f} \cos \left(2 \pi f t-m \alpha_{s}+\phi_{m f}\right)
$$

A resonance occurs at two conditions [9]: the order of the force harmonic must be the same as the circumferential mode number of the stator, and the frequency of the force harmonic must be the same as the frequency of the natural frequency of the stator mode under consideration. The former condition is not reported in [10], but it is as important as the frequency match condition. In variable-speed motors, this frequency match condition is more easily satisfied as the frequencies of magnetic forces due to fundamental current vary proportionally to the supply frequency $f_{s}$, and therefore sweep a wide frequency range during starting and braking.

To predict resonances, one must therefore analytically calculate the Fourier development of $P_{M}$. It can be done using a permeance / $\mathrm{mmf}$ decomposition of the radial flux density [11], [12]. In the no-load case, this decomposition is given by

$$
B_{g}=\Lambda f_{m m}^{s}=\frac{\mu_{0}}{g_{f}} f_{m m}^{s}
$$

where $g_{f}$ is the air-gap "magnetic length", i.e. the mean length of flux density lines that equals $g, g+d_{f}^{s}, g+d_{f}^{r}$ or $g+d_{f}^{s}+d_{f}^{r}$ according to the respective position of stator and rotor slots. The Fourier development of both permeance and mmf can be found in [13], [14], as well as the flux density spectrum resulting from their product, and the radial force spectrum obtained from the product of flux density harmonics.

\section{B. Characterization of main Maxwell slotting harmonics}

All these combinations give numerous force waves. However, the higher their spatial order is, the lower stator static deflection is [7]. Moreover, some of them have very low magnitude as they come from the multiplication of low magnitude harmonics (e.g. a high order mmf space harmonic combined with a high order permeance harmonics gives a very low flux density harmonic). Finally, some of these harmonics have low frequencies (less than $400 \mathrm{~Hz}$ ), far from human's ear maximal sensitivity range.

Neglecting these force waves, one can find that they can be reduced to three main families assuming that currents are sinusoidal [15], [16]:

1) slotting force harmonics, coming from the interaction of some rotor and stator slotting permeance harmonics with twice the stator mmf fundamental (magnitude $\left.P_{s} P_{r} F_{s} F_{s} /\left(2 \mu_{0}\right)\right)$

2) "winding force" harmonics, coming from the interaction of some rotor and stator slotting permeance harmonics with the stator mmf fundamental, and with one stator mmf space harmonic (magnitude $P_{s} P_{r} F_{s} F_{h} /\left(2 \mu_{0}\right)$ )

3) saturation force harmonics, coming from the interaction of a slotting permeance harmonic with a saturation permeance harmonic, and with the square stator $\mathrm{mmf}$ fundamental (magnitude $P_{s r} P_{a} F_{s} F_{s} /\left(2 \mu_{0}\right)$ )

Saturation of teeth indeed flattens the air-gap flux density, which modifies the space harmonic content of Maxwell forces, and can change magnetic noise level [7], [17]. This effect can be modeled by adding to the permeance function the additional permeance harmonics due to saturation with spatial order $2 p k_{a}$, where $k_{a}$ is a positive integer [11], [18], [19].

In a moderately saturated short-pitched induction machine, winding and saturation noise are negligible [16], and the main source of magnetic noise comes from slotting force harmonics. They can be represented by three families, whose characteristics (spatial orders and frequencies) are presented in Table I. All the frequencies of these force waves are here positive, so their propagation direction is encoded with negative spatial orders.

TABLE I

SLOTTING FORCE HARMONICS CHARACTERIZATION.

\begin{tabular}{|l|c|c|}
\hline Name & Frequency $f$ & Spatial order $m$ \\
\hline$F_{\text {slot }}^{-}$ & $f_{s}\left(k_{r} Z_{r}(1-s) / p-2\right)$ & $k_{r} Z_{r}-k_{s} Z_{s}-2 p$ \\
$F_{\text {slot }}^{0}$ & $f_{s}\left(k_{r} Z_{r}(1-s) / p\right)$ & $k_{r} Z_{r}-k_{s} Z_{s}$ \\
$F_{\text {slot }}^{+}$ & $f_{s}\left(k_{r} Z_{r}(1-s) / p+2\right)$ & $k_{r} Z_{r}-k_{s} Z_{s}+2 p$ \\
\hline
\end{tabular}

$k_{r}$ and $k_{s}$ are strictly positive integers appearing in the Fourier series of permeance distribution: they respectively account for rotor slotting and stator slotting. The three families $F_{\text {slot }}^{-}, F_{\text {slot }}^{0}$ and $F_{\text {slot }}^{+}$therefore stand for an infinite number of force harmonics, but the higher are $k_{r}$ and $k_{s}$, the lower are rotor and stator slotting permeance harmonics, and the lower is the corresponding force harmonic. The highest magnitude force harmonics are given by $k_{s}=k_{r}=1$, but they do not necessarily create high vibrations as their associated order $m=k_{r} Z_{r}-k_{s} Z_{s} \pm 0,2 p$ can be very high. Note that as the only rotating part is the rotor, $k_{s}$ and $Z_{s}$ do not appear in the frequency expression of slotting force harmonics.

The force waves magnitude $F_{\text {slot }}^{-}$and $F_{\text {slot }}^{+}$are the same, but $F_{\text {slot }}^{0}$ force waves are twice higher as they represent the interaction of two different force waves of frequencies $f_{s}\left(k_{r} Z_{r}(1-s) / p+1-1\right)$ and $f_{s}\left(k_{r} Z_{r}(1-s) / p-1+1\right)$ [16]. However, their magnitude $F_{\text {slot }}$ is always proportional to [14], [20]

$$
F_{\text {slot }} \propto P_{s} P_{r} \propto \frac{\sin \left(\pi k_{r} s l_{r}\right)}{k_{r}} \frac{\sin \left(\pi k_{s} s l_{s}\right)}{k_{s}}
$$

where the slotting ratios $s l_{s}$ and $s l_{r}$ are given by

$$
s l_{s}=1-\frac{b_{s}}{\tau_{s}} \quad s l_{r}=1-\frac{b_{r}}{\tau_{r}}
$$

All these force waves characteristics have been validated by experimentally visualizing the stator stack deflection at a given frequency [21]. As an example, a motor with $Z_{s}=27$, $Z_{r}=21$ and $p=2$ creates a slotting Maxwell force harmonic for $k_{s}=k_{r}=1$ of order $Z_{r}-Z_{s}+2 p=-2$ with frequency $f_{s}\left(Z_{r}(1-s) / p-2\right)$. This was validated by measuring the acceleration of 16 points around the stator median circumference, when feeding the motor with $50 \mathrm{~Hz}$ sinusoidal currents, and visualizing the operational deflection shape of the stator 
with Pulse Labshop at frequency $f_{s}\left(Z_{r}(1-s) / p-2\right) \approx 375$ $\mathrm{Hz}$ (Fig. 1).

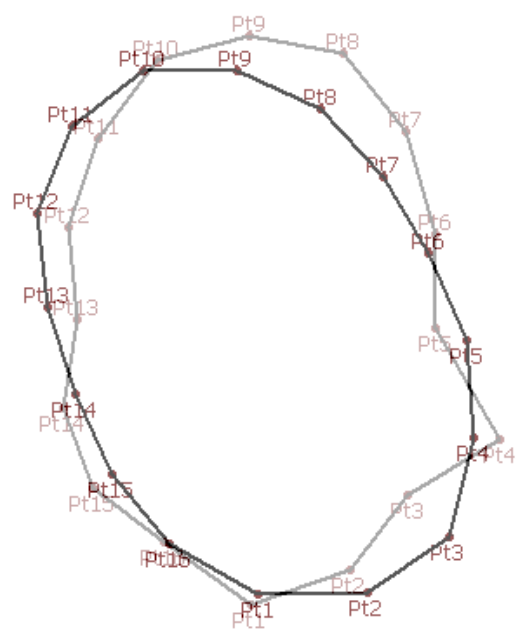

Fig. 1. Stator deflection of order $-2=Z_{r}-Z_{s}+2 p$ due to a slotting vibration. The grey deflection stands for a previous time, showing that the vibration wave travels in counter-clockwise direction as its spatial order is negative.

\section{MAgnetic NOISE REDUCTION TECHNIQUE}

\section{A. Principle}

Two methods can be used to avoid high levels of magnetic noise: the first one consists in avoiding resonances between the exciting forces and the excited structure, by properly choosing the slot combinations that have an influence on both the exciting force frequencies and spatial orders (cf. Table I). This is what is done for instance in [17] for magnetic noise due to saturation harmonics. A second method consists in reducing the exciting forces magnitude by choosing properly the slot geometry. In this paper, it is assumed that the designer has already chosen the motor slot numbers, and wants to reduce the magnitude of the existing slotting magnetic forces.

Once a low-order slotting force harmonic linked to integers $k_{r 0}$ and $k_{s 0}$ is known to possibly resonate with the corresponding stator mode, it is possible to cancel its magnitude by properly choosing the rotor or stator slot opening value. Equation (4) indeed contains sine functions that can equal zero if

$$
k_{r 0} s l_{r}=i_{0} \quad \text { or } \quad k_{s 0} s l_{s}=j_{0}
$$

where $i_{0}$ and $j_{0}$ are non-zero relative integers. It is theoretically sufficient to cancel either $P_{r}$ or $P_{s}$ permeance harmonic magnitude, but the designer can try to cancel both in order to make the design more robust, in particular to minimize the effect of manufacturing errors. It is easier to fulfill both conditions when designing a new motor from scratch : when trying to minimize magnetic noise of a given motor, manufacturing a new rotor is less expensive, and the aimed equality is then reduced to $k_{r 0} s l_{r}=i_{0}$.
If two dangerous slotting force harmonics are identified linked to integers $\left(k_{r 0}, k_{s 0}\right)$ and $\left(k_{r 1}, k_{s 1}\right)$, the designer can also optimize the stator slot geometry in order to obtain the condition $k_{s 0} s l_{s}=j_{0}$ that cancels the first vibration, and independently choose the rotor geometry to obtain the condition $k_{r 1} s l_{r}=j_{1}$, so that the second vibration is canceled.

To precise these conditions, as $s l_{r}$ and $s l_{s}$ values lie between 0 and 1 , they can be expressed as

$$
b_{r}=\tau_{r}\left(1-\frac{i_{0}}{k_{r 0}}\right), \quad i_{0} \in\left[1, k_{r 0}-1\right]
$$

and

$$
b_{s}=\tau_{s}\left(1-\frac{j_{0}}{k_{s 0}}\right), \quad j_{0} \in\left[1, k_{s 0}-1\right]
$$

For $k_{r 0}=k_{s 0}=1$, there does not exist any slot opening values canceling the slotting vibration, apart the particular cases of $s l_{r}=0$ or $s l_{s}=0$ (no rotor or stator teeth), and $s l_{r}=1$ or $s l_{s}=1$ (fully closed rotor or stator slots). This technique is only applicable when $k_{r 0} \geq 2$ or $k_{s 0} \geq 2$, which is the more common case. Note that this technique gives a set of optimal slot opening values, which allows the designer choosing among these best values. However, the lower $k_{r 0}$ and $k_{s 0}$ are, the higher is the slotting vibration magnitude to reduce, and the smaller are the numbers of optimal slot opening values.

This technique can lead to relatively wide slot opening values, especially when $k_{s 0}$ and $k_{r 0}$ are low, as

$$
b_{r} \geq \tau_{r} / k_{r 0} \quad b_{s} \geq \tau_{s} / k_{s 0}
$$

Consequently, the reduction of a slotting vibration on a given motor can lead to wider slot opening widths, which increases some other slotting vibrations magnitude. The technique must therefore be applied to the noisiest slotting vibration in order to be sure that the enlargement of slot opening widths up to the smallest optimal value will globally reduce magnetic noise.

At the rotor, the smallest optimal value of slot opening is given by

$$
b_{r}^{o p t}=\tau_{r} / k_{r 0}
$$

This configuration is illustrated in Fig. 2 for trapezoidal semi-closed rotor slots, a slot geometry often used in traction motors. Notice that equation (10) also cancels all the slotting vibrations linked to $k_{r}$ that are multiples of $k_{r 0}$ as $s l_{r} k_{r 0}$ becomes an integer.

Assuming that stator slots are opened rectangular slots (as used in railway traction application, where nominal output power lie between 150 and $250 \mathrm{~kW}$ ), the best stator slot opening optimal value is not the smallest one because enough room must be left for windings. The ratio between air and iron in stator slotting is generally close to one, i.e. $b_{s} \approx \tau_{s} / 2$. If $k_{s 0}$ is even $\left(k_{s 0}=2 m_{s 0}\right)$, one can easily see that the optimal value of stator slot opening can be reached by $j_{0}=m_{s 0}$ and give

$$
b_{s}^{o p t}=\tau_{s} / 2
$$




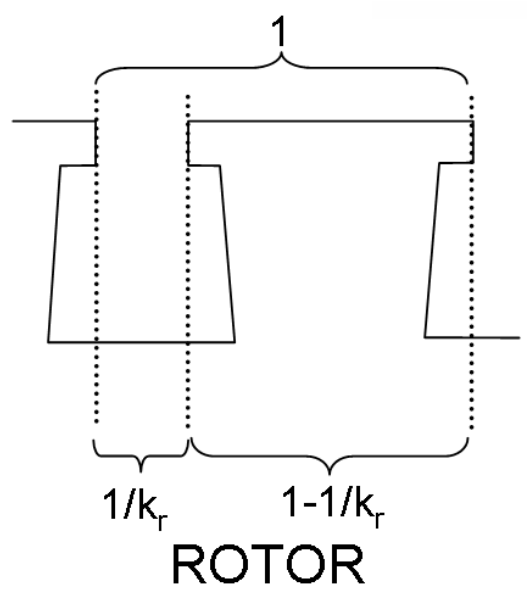

Fig. 2. Illustration of the smallest optimal rotor slot opening value cancelling a slotting vibration linked to the rotor permeance slotting harmonic number $k_{r}\left(k_{r}=4\right.$ is used in this example).

Similarly to rotor slot case, if $b_{s}=\tau_{s} / 2$, all the slotting harmonics linked to even $k_{s 0}$ are automatically canceled as $s l_{s} k_{s 0}$ is an integer. Such a configuration is illustrated in Fig. 3 .

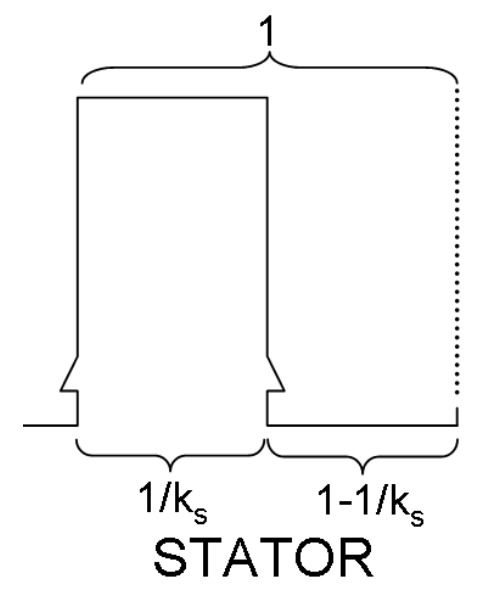

Fig. 3. Illustration of the smallest optimal stator slot opening value canceling a slotting vibration linked the stator permeance slotting harmonic number $k_{s}$ $\left(k_{s}=2\right.$ is used in this example, it also gives a unitary air/iron ratio that cancels all the slotting harmonics linked to even $k_{s}$ ).

On the contrary, if $k_{s 0}$ is odd $\left(k_{s 0}=2 m_{s 0}+1\right)$, one can see that the two optimal opening width values that give an air/iron ratio the closest from the unity are

$$
b_{s}^{o p t 1}=\tau_{s} \frac{m_{s 0}}{k_{s 0}}, \quad b_{s}^{o p t 2}=\tau_{s} \frac{m_{s 0}+1}{k_{s 0}}
$$

If possible, the smallest value $b_{s}^{o p t 1}$ is the best one as it limits the other slotting harmonics magnitude. If the designer does not want the closest air/iron ratio to one at the stator, and needs more room for winding, he can use some wider stator slot optimal widths, but he must be aware that it will make stator teeth thinner, enlarging tangential magnetic vibrations [22]. Some stiffer wedges are then recommended in order to limit these new vibrations.
The choice of rotor and stator slot opening value for magnetic noise reduction has also an influence on slot leakage flux. Nevertheless, as explained before, the strongest magnetic noise lines are associated to low $k_{r 0}$ and $k_{s 0}$, leading to relatively wide optimal slot openings, so that magnetic noise and slot leakage can be both reduced: the proposed technique does not penalize the motor starting torque and current.

\section{B. Numerical simulation}

In this part are presented some simulation results using a simulation tool called DIVA [14], which is able to determine the acoustic noise of magnetic source emitted by an induction machine. This vibro-acoustic simulation software has been already validated on several motors [16], [23], [21], [24], [25].

Let's consider an induction machine with $Z_{s}=48, Z_{r}=36$ and $p=2$. By computing all the slotting vibrations for $k_{r}$ and $k_{s}$ going from 1 to 10 , one can find the only low-order slotting vibrations of Table II.

TABLE II

MAIN SLOTTING FORCE HARMONICS CHARACTERIZATION FOR $Z_{s}=48$,

$$
Z_{r}=36 \text { AND } p=2 .
$$

\begin{tabular}{|c|c|c|c|c|}
\hline Name & $k_{r}$ & $k_{s}$ & $f$ & $m$ \\
\hline$F_{\text {slot }}^{-}$ & 4 & 3 & $f_{s}\left(4 Z_{r}(1-s) / p-2\right)$ & $-4=4 Z_{r}-3 Z_{s}-2 p$ \\
$F_{\text {slot }}^{0}$ & 4 & 3 & $f_{s}\left(4 Z_{r}(1-s) / p\right)$ & $0=4 Z_{r}-3 Z_{s}$ \\
$F_{\text {slot }}^{+}$ & 4 & 3 & $f_{s}\left(4 Z_{r}(1-s) / p+2\right)$ & $4=4 Z_{r}-3 Z_{s}+2 p$ \\
$F_{\text {slot }}^{-}$ & 8 & 6 & $f_{s}\left(8 Z_{r}(1-s) / p-2\right)$ & $-4=8 Z_{r}-6 Z_{s}-2 p$ \\
$F_{\text {slot }}^{0}$ & 8 & 6 & $f_{s}\left(8 Z_{r}(1-s) / p\right)$ & $0=8 Z_{r}-6 Z_{s}$ \\
$F_{\text {slot }}^{+}$ & 8 & 6 & $f_{s}\left(8 Z_{r}(1-s) / p+2\right)$ & $4=8 Z_{r}-6 Z_{s}+2 p$ \\
\hline
\end{tabular}

In that example, we can see that all the slotting vibrations are linked with $k_{r}$ multiples of 4 . All these lines can be theoretically canceled by choosing $b_{r}$ according to equation (10), i.e. with $b_{r}=\tau_{r} / 4$ (cf. Fig. 2). This fact has been checked by simulations, comparing the noise spectrum radiated by an induction with a non-optimal rotor slot opening $\left(\tau_{r}=26 \mathrm{~mm}, b_{r}=3.5 \mathrm{~mm}\right)$ with a new one where the rotor slot opening width has been changed according to equation (10) $\left(\tau_{r}=26 \mathrm{~mm}, b_{r}=6.5 \mathrm{~mm}\right)$. Results are displayed in Fig. 4, where the chosen supply frequency creates a resonance between the exciting slotting force harmonic $F_{\text {slot }}^{0}$ and the stator breathing mode number 0: main slotting lines are canceled in agreement with theory, decreasing the global magnetic noise of $20 \mathrm{~dB}$, and the other magnetic noise spectrum lines are slightly increased due to a larger rotor slot opening. This technique therefore significantly decreases magnetic noise level at resonance.

Some other simulations have been run in order to quantify how much errors on the optimal slot opening value affect the magnetic sound power level. The sensitivity of the optimal $b_{r}$ value is illustrated in Fig. 5, where the noise associated to the slotting line $F_{\text {slot }}^{0}\left(k_{s 0}=3, k_{r 0}=4\right)$ has been computed in function of $b_{r}$. We can see that a $5 \%$ error on the optimal value highers the noise level from 0 to $57 \mathrm{~dB}$, the maximum noise level being $73 \mathrm{~dB}$. Such an error can be relativised as a magnetic noise line inferior to $60 \mathrm{~dB}$ may be covered by some higher magnetic lines, ambient noise or other sources of noise (fan noise, gearbox noise, etc). 

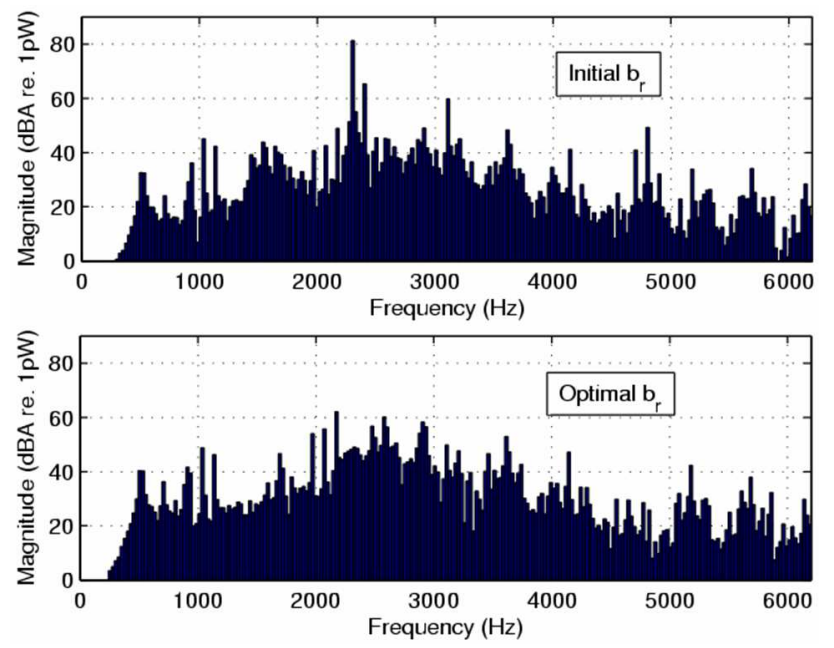

Fig. 4. A-weighted sound pressure level spectrum, for the initial rotor slot opening value (upper figure) and the optimal value (lower figure).

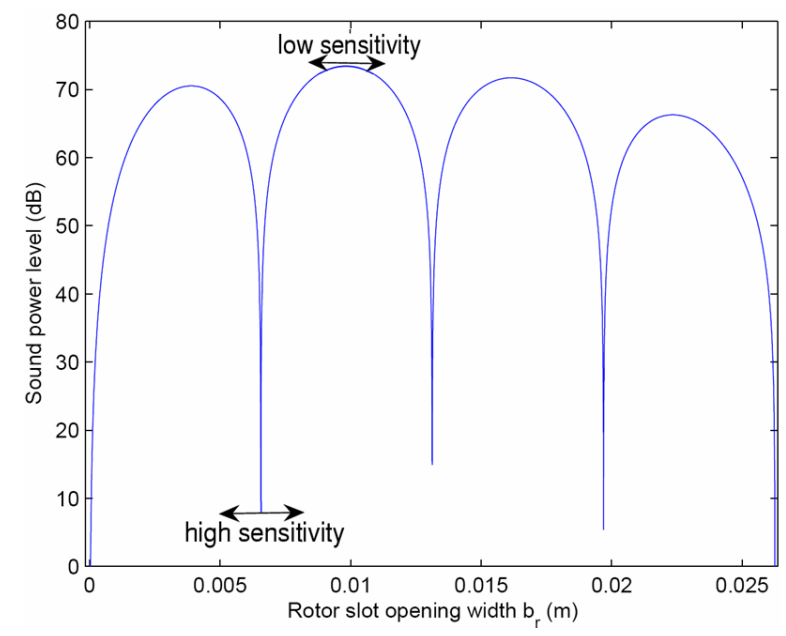

Fig. 5. Sound power level radiated by the slotting line $F_{\text {slot }}^{0}$ associated to $k_{s 0}=3$ and $k_{r 0}=4$ in function of the rotor slot opening $b_{r}$ varying from 0 to $\tau_{r}$. The second to the fourth local minimums correspond to the three $b_{r}$ values of equation (7); they do not totally cancel noise due to the finite discretization step used for $b_{r}$ in simulations.

\section{Experimental validation}

A new rotor with $b_{r}=6.5 \mathrm{~mm}$ has been built to check the efficiency of this technique. In agreement with simulations, the main slotting lines identified in Table II were the largest lines observed in the acoustic spectrum. Moreover, they were very low $\left(\approx 55 \mathrm{dBA}\right.$ for the three slotting lines linked to $k_{r}=4$ and $k_{s}=3$, close to the ambient noise level), showing that the technique has successfully weakened the aimed slotting vibrations.

Slotting lines were not completely canceled due to saturation effects that tend to enlarge the rotor slot openings. Consequently, the optimal value of equation (10) should be slightly underestimated to account for saturation effect. This effect can be quantified using for instance the analytical law proposed in [26].

Some other acoustic tests have been run feeding the motor with asynchronous Pulse-Width Modulation (PWM) at

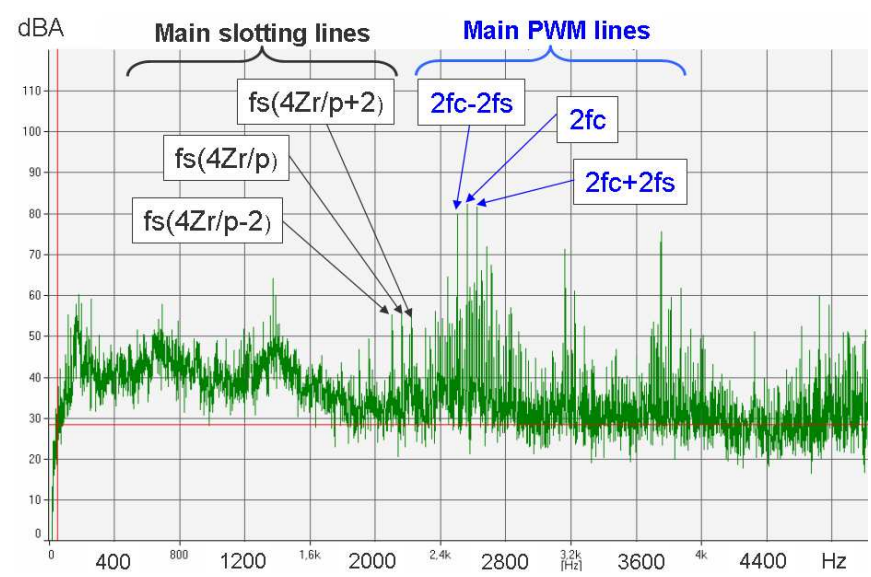

Fig. 6. Sound pressure level spectrum of new prototype with $b_{r}=6.5 \mathrm{~mm}$ (asynchronous PWM at $1280 \mathrm{~Hz}, s \approx 0$ ).

$f_{c}=1280 \mathrm{~Hz}$ switching frequency. PWM enriches the Maxwell force spectrum by adding current harmonics; as the fundamental current remains unchanged, magnetic noise due to PWM is always superior to magnetic noise in sinusoidal case.

In our experiments, it was observed that PWM acoustic lines completely dominate the overall sound power level (see Fig. 6 where canceled slotting lines only reach $55 \mathrm{dBA}$, in agreement with a $5 \%$ error on $b_{r}$ optimal value as shown by simulations): slotting lines have been significantly reduced, and the only significant lines near $2 f_{c}$ and $4 f_{c}$ frequencies are due to PWM [15]. Other lines at $f_{c}, 3 f_{c}$ are also linked due to PWM, as well as the line near $3200 \mathrm{~Hz}$ that comes from the combination between slotting and PWM harmonics [16], [21].

The differences between Fig. 6 experimental spectrum and Fig. 4 simulation results are mainly explained by the mechanical, aerodynamic, ambient noise and PWM noise due to switching harmonics in experiments that were not accounted for in simulations.

\section{CONCLUSION}

A new magnetic noise reduction technique is demonstrated and validated, relying on the optimal choice of rotor or stator slot opening widths once the slotting vibrations to cancel have been analytically characterized. This technique do not increase slot leakage inductance ; it can be applied during the design stage of induction machines, and let a degree of freedom to the designer who can choose the quiet slot opening width in a set of different values. It shows that contrary to the common design rule that advices to decrease rotor and stator slot openings width in order to reduce magnetic noise, a wider slot opening can lower the noise level if properly chosen.

Furthermore, this technique can be applied to any magnetic force wave related to permeance harmonic: besides slotting vibrations, it can efficiently cancel a "winding vibration", or a saturation vibration (cf. section II-B where their magnitude are proportional to $P_{s} P_{r}$ or $P_{s r}$ ) that can be noisy in starting traction motors. As it leads to relatively large slot openings, this technique also decreases slot leakage inductances. 
Once that technique is used, PWM noise dominates slotting noise, so further work aims at finding new design rules reducing PWM vibrations.

\section{REFERENCES}

[1] W. Finley, "Noise in induction motors - causes and treatments," IEEE Trans. on Ind. Appl., vol. 27, no. 6, pp. 1204-1213, 1991.

[2] "Electric traction - Rotating electrical machines for rail and road vehicles - Part 2: Electronic convertor-fed alternating current motors," IEC 60349-2-2002 standard.

[3] R. Corton, H. Sawezyn, D. Belkhayat, and J. Brudny, "Principe of magnetic noise active reduction using three phase systems due to PWM inverter switching," in $2^{\text {nd }}$ International Seminar on Vibrations and Acoustic Noise of Electric Machinery (VANEM), pp. 157-152, 2000.

[4] B. Cassoret, R. Corton, D. Roger, and J. Brudny, "Magnetic noise reduction of induction machines," IEEE Trans. on Power Electronics, vol. 18, pp. 570-579, Mar. 2003.

[5] D. Belkhayat, D. Roger, and J. Brudny, "Active reduction of magnetic noise in asynchronous machine controlled by stator current harmonics," in Proc. of EMD conference, pp. 400-405, Sept. 1998.

[6] P. Alger, Induction machines : their behaviour and uses. Gordon and Breach Science Publishers, 1970.

[7] P. Timar, Noise and vibration of electrical machines. Elsever, 1989.

[8] H. Jordan, Electric motor silencer - formation and elimination of the noises in the electric motors. W. Giradet-Essen editor, 1950.

[9] W. Soedel, Vibrations of shells and plates. Marcel Dekker, 1993.

[10] P. Vijayraghavan and R. Krishnan, "Noise in electric machines: a review," IEEE Trans. on I.A.S., vol. 35, pp. 1007-1013, Oct. 1999.

[11] S. Verma and A. Balan, "Determination of radial-forces in relation to noise and vibration problems of squirrel-cage induction motors," IEEE Trans. on En. Conv., vol. 9, pp. 404-412, June 1994.

[12] J. Lecointe, R. Romary, J. Brudny, and M. McClelland, "Analysis and active reduction of vibration and acoustic noise in the switched reluctance motor," IEE Proc. on Power Appl., vol. 151, pp. 725-733, Nov. 2004.

[13] M. Poloujadoff, "General rotating mmf theory of squirrel cage induction machines with non-uniform air gap and several non sinusoidally distributed windings," IEEE Trans. on P.A.S, vol. 101, pp. 583-591, Mar. 1982.

[14] J. Le Besnerais, V. Lanfranchi, M. Hecquet, P. Brochet, and G. Friedrich, "Acoustic noise of electromagnetic origin in a fractional-slot induction machine," COMPEL, vol. 27, pp. 1033 - 1052, Feb. 2008

[15] W. Lo, C. Chan, Z. Zhu, L. Xu, D. Howe, and K. Chau, "Acoustic noise radiated by PWM-controlled induction machine drives," IEEE Trans. on Industrial Electronics, vol. 47, pp. 880-889, Aug. 2000.

[16] J. Le Besnerais, Reduction of magnetic noise in PWM-supplied induction machines - low-noise design rules and multi-objective optimisation. $\mathrm{PhD}$ thesis, Ecole Centrale de Lille, France, Nov. 2008.

[17] J. Le Besnerais, V. Lanfranchi, M. Hecquet, G. Lemaire, E. Augis, and P. Brochet, "Charaterization and reduction of magnetic noise due to saturation in induction machines," IEEE Trans. on Mag. Accepted for publication.

[18] K. Maliti, Modelling and analysis of magnetic noise in squirrel-cage induction motors. $\mathrm{PhD}$ thesis, Stockholm, 2000.

[19] J. Moreira and T. Lipo, "Modeling of saturated AC machines including air gap flux harmonics components," IEEE Trans. on Ind. Appl., vol. 28 no. 2, pp. 343-349, 1992.

[20] J. Brudny, Etude quantitative des harmoniques du couple du moteur asynchrone triphasé d'induction. Université des Sciences et Technologies de Lille, FRANCE: Habilitation à Diriger des Recherches, 1991.

[21] J. Le Besnerais, V. Lanfranchi, M. Hecquet, P. Brochet, and G. Friedrich, "Characterisation of the radial vibration force and vibration behaviour of a PWM-fed fractional-slot induction machine," IET Electric Power Applications, Feb. 2009.

[22] S. Garvey and G. L. Flem, "Tangential forces matter," Proc. 9th Int. Conf. Electrical Machines and Drives, pp. 174-178, 1999.

[23] J. Le Besnerais, V. Lanfranchi, M. Hecquet, and P. Brochet, "Multiobjective optimization of induction machines including mixed variables and noise minimization," IEEE Trans. on Mag., vol. 44, pp. 1102 1105, June 2008.

[24] J. Le Besnerais, V. Lanfranchi, M. Hecquet, and P. Brochet, "Characterization of the audible magnetic noise emitted by traction motor in railway rolling stock," in Proc. of the INTERNOISE conference, (Shanghai, China), Oct. 2008.
[25] J. Le Besnerais, A. Fasquelle, J. Pelle, S. Harmand, M. Hecquet, V. Lanfranchi, P. Brochet, and A. Randria, "Multiphysics modeling: electro-vibro-acoustics and heat transfer of induction machines," in Proc. of the International Conference on Electrical Machines (ICEM'08), (Villamura, Portugual), Sept. 2008.

[26] J. Gieras, C. Wang, and J. Lai, Noise of polyphase electric motors. CRC Press, Dec. 2005.

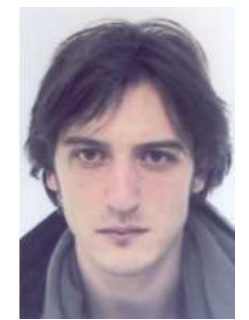

Jean Le Besnerais received its Master in Engineering, Applied Mathematics, in 2005 at the Ecole Centrale Paris, France. He then obtained his Ph.D. degree in Electrical Engineering in 2008 at the Laboratoire d'Electrotechnique et d'Electronique de Puissance (L2EP, http://12ep.univ-lille1.fr/), Ecole Centrale de Lille, in the Optimization team. His research interests include analytical modeling of induction machines, magnetic noise and vibration issues in PWM-fed electrical machines, and optimization methods.

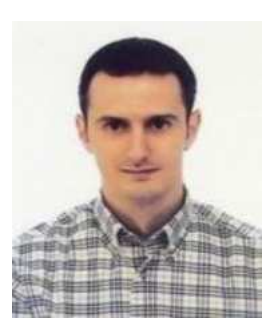

Vincent Lanfranchi received his Ph.D. degree in electrical engineering from the University of Reims (France) in 2000. Since 2001 he has been an Associate Professor at the Universite de Technologie de Compiegne. His teaching areas are electrical engineering and mechatronics. He is a researcher in the LEC laboratory (Laboratoire d'Electromécanique de Compiègne). His main research interests are converter-machine interactions and Pulse Width Modulation strategies.

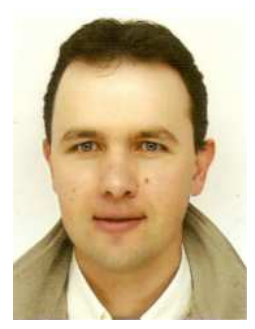

Michel Hecquet received his Ph.D. degree in electrical engineering from the University of Lille, France, in 1995. His research interests include the modeling, the design and the optimization of electrical machines, particularly the application of the experimental designs methodology to finite element models. $\mathrm{He}$ is interested in the development and application of multi-physics models of electrical machines (electromagnetic, mechanical and acoustic) in view of their optimal design. He is now working in the L2EP as an associate professor and researcher.

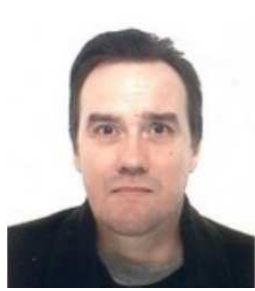

Raphael Romary was born in 1967. He received the Ph.D. degree from the University of Lille I (France) in 1995 and the D.Sc. degree in 2007 from the Artois University (France). He is currently an assistant professor in the Artois University. His research activities are performed in the Laboratory of Electromechanical Systems and Environment (LSEE) of the Artois University. His research interests include analytical modeling of electrical machines with applications to the study of vibrations, magnetic noise, losses, emitted magnetic field and diagnosis. 


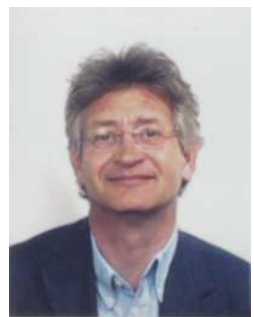

Pascal Brochet received a Ph.D. in Numerical Analysis in 1983 at the Université des Sciences et Technologies de Lille. He worked during seven years in an Automotive Equipment Company as a research engineer in the field of computer aided design of electrical machines. He then joined the

Ecole Centrale de Lille in 1990 where he is now full professor and researcher at the L2EP laboratory. His main interests are numerical simulation, design and optimization of electrical machines. 